\title{
Combining Living Microorganisms with Regenerated Silk Provides Nanofibril-Based Thin Films with Heat-Responsive Wrinkled States for Smart Food Packaging
}

\author{
Luca Valentini ${ }^{1, *}$, Silvia Bittolo Bon ${ }^{1}$ (1) and Nicola M. Pugno ${ }^{2,3,4, *}$ \\ 1 Dipartimento di Ingegneria Civile e Ambientale, Università di Perugia, UdR INSTM, Strada di Pentima 4, \\ 05100 Terni, Italy; silvia.bittolo@gmail.com \\ 2 Laboratory of Bio-Inspired and Graphene Nanomechanics, Department of Civil, Environmental and \\ Mechanical Engineering, University of Trento, I-38123 Trento, Italy \\ 3 School of Engineering and Materials Science, Queen Mary University of London, Mile End Road, \\ London E1 4NS, UK \\ 4 Ket-Lab, Edoardo Amaldi Foundation, Italian Space Agency, via del Politecnico snc, I-00133 Roma, Italy \\ * Correspondence: luca.valentini@unipg.it (L.V.); nicola.pugno@unitn.it (N.M.P.); Tel.: +39-0744-492-924 (L.V.); \\ +39-0461-282-525 (N.M.P.)
}

Received: 19 June 2018; Accepted: 10 July 2018; Published: 11 July 2018

\begin{abstract}
Regenerated silk (RS) is a protein-based "biopolymer" that enables the design of new materials; here, we called "bionic" the process of regenerated silk production by a fermentation-assisted method. Based on yeast's fermentation, here we produced a living hybrid composite made of regenerated silk nanofibrils and a single-cell fungi, the Saccharomyces cerevisiae yeast extract, by fermentation of such microorganisms at room temperature in a dissolution bath of silkworm silk fibers. The fermentation-based processing enhances the beta-sheet content of the $\mathrm{RS}$, corresponding to a reduction in water permeability and $\mathrm{CO}_{2}$ diffusion through $\mathrm{RS} /$ yeast thin films enabling the fabrication of a mechanically robust film that enhances food storage durability. Finally, a transfer print method, which consists of transferring RS and RS/yeast film layers onto a self-adherent paraffin substrate, was used for the realization of heat-responsive wrinkles by exploiting the high thermal expansion of the paraffin substrate that regulates the applied strain, resulting in a switchable coating morphology from the wrinkle-free state to a wrinkled state if the food temperature overcomes a designed threshold. We envision that such efficient and smart coatings can be applied for the realization of smart packaging that, through such a temperature-sensing mechanism, can be used to control food storage conditions.
\end{abstract}

Keywords: bionic composites; thin films; mechanical properties

\section{Introduction}

Living microorganisms have long been used in food preservation [1,2]; such microorganisms form living surfaces that provide an attractive platform for the development of functional materials. At present, biotech companies uses fungi to produce valuable products [3]; thus, combining the fermentation mechanism of some microorganisms with biomaterials could give rise to bionic composites with novel properties.

Among such novel products, the development of innovative packaging solutions to increase the shelf-life of fresh fruits by slowing down their metabolism so they remain fresh and appetizing for longer, and sensors to monitor if perishable food in the cold chain is maintained in the desired 
temperature range to prevent the growth of pathogens and spoilage microorganisms, remains a challenge. To date, biodegradable polymers (i.e., polylactic acid or polylactide (PLA), polyglycolic acid or polyglycolide (PGA), poly-caprolactone (PCL), and polyhydroxybutyrate (PHB)) have been explored for food packaging due to mechanical robustness of the matrix with hydrophobic chain groups that allow for low permeability to oxygen and water vapours [4]. However, their biocompatibility, lamination without solvent-based adhesives, and sensing properties are still challenging aspects for their utilization in smart packaging applications.

Concerning the sensing issue, the spontaneous generation of wrinkles induced by the buckling of a thin skin due to thermal contraction of the underlying substrate may be used as smart sensors for monitoring temperature changes in a food cold chain. In this regard, micro/nanoscale surface patterns obtained by coupling a stiff skin to a soft substrate have been used to create reversible patterns that are responsive to temperature and provide a unique surface morphology to sense temperature changes [5-7].

From the material point of view, silk fibroin is an ideal candidate for packaging applications since it is a biocompatible structural protein that can be processed to obtain films which recently have been used as biodegradable and edible sensors to monitor food degradation [8-10]. The polymorphism of silk fibroin (i.e., random coil, silk I, and silk II structures) can be also tailored by controlling the content of $\beta$-sheet crystals to enable the correct gas exchange and water vapour permeability through silk-based membranes [11-13]. Among the different fabrication methods, transfer printing is the most known method for interfacing silk on soft substrates [14]. In this regard, the hidden strength and stiffness of natural honeycomb walls constructed from recycled silk and wax secreted by worker bees [15-17] is reminiscent of modern fiber-reinforced composite laminates.

Taking inspiration from the honeybee comb cell wall, a self-adhesive and soft thermoplastic paraffin wax can be used to stick a regenerated silk (RS) film to produce a bilayer system [18]. Being the paraffin wax a material with a high thermal expansion coefficient, wrinkles occur to minimize the total energy of such a bilayer system when the compressive strain, caused by the thermal expansion coefficients and rigidities, mismatches between the skin layer and the substrate induced by thermal stimulus.

Inspired by our previous work where the metabolic activity of living microorganisms was used as an engineered platform for the fabrication of advanced carbon-based materials [19], here we extend this approach, with emphasis on the fermentation process used for centuries in wine- and bread-making, to produce bionic composites which integrate regenerated silk nanofibrils that from the geometrical point of view and in terms of mechanical properties are similar to carbon nanotubes. The resulting reduced volume fraction of nanofibrils within the film could make the fermented hybrid composite more resistant to fracture with self-repairing properties exploiting the microorganisms' growth process that allows for the intracellular transport of nanomaterials, and the $\mathrm{CO}_{2}$ bubbles produced during fermentation could be used to produce porous architectures for biomedical applications. Here, it was observed that once Saccharomyces cerevisiae yeast cells were fermented by nutrient addition into a silk fibroin solution, the regenerated silk shows a higher content of beta-sheet structures. Moreover, the microorganism growth increased the cell density and reduced the porosity of the RS membrane, limiting the exchange of water and gas diffusion. As conceptual proof, we demonstrated as an example that the deposition of such a living coating on fruits helps the preservation of their shelf-life. Finally, we demonstrate that RS-based film layers can be laminated onto a paraffin wax substrate for the realization of temperature-responsive bilayer system.

\section{Materials and Methods}

For the preparation of the RS film, commercial Bombyx mori silk cocoons were boiled for $1 \mathrm{~h}$ in a distillated water solution of $0.025 \mathrm{wt} \% \mathrm{NaHCO}_{3}$ rinsed with distilled water every $30 \mathrm{~min}$ to remove the sericin. According to the method adopted by Kaplan et al. [20], the degummed silk (i.e., 0.2 g) was then added to a $\mathrm{CaCl}_{2}$ (i.e., $0.14 \mathrm{~g}$ ) and $\mathrm{CH}_{2} \mathrm{O}_{2}$ (formic acid) (i.e., $20 \mathrm{~mL}$ ) solution mixture and stirred 
overnight at $40{ }^{\circ} \mathrm{C}$ to yield a $1 \mathrm{wt} \%$ solution. A water solution $(50 \mathrm{mg} / \mathrm{mL})$ of a Saccharomyces cerevisiae (Lesaffre Italia S.p.A. S. Quirico, Tre Casali, Italy)-based beer yeast extract was prepared separately by mechanical stirring at $30{ }^{\circ} \mathrm{C}$ for $1 \mathrm{~h}$. After that, $0.4 \mathrm{~g}$ of sucrose was added to $20 \mathrm{cc}$ of water to start the fermentation. The water solution of fermenting yeast was then added to the silk fibroin solution. RS/yeast films were prepared by leaving the silk-yeast solution to evaporate for $12 \mathrm{~h}$ in a polystyrene Petri dish (diameter $15 \mathrm{~cm}$ ). The growth of yeast cells was monitored by the optical density (OD) method, measuring the absorbance at a wavelength of $600 \mathrm{~nm}$ and a temperature of $30{ }^{\circ} \mathrm{C}$ of the yeast and RS/yeast solutions in sucrose growth medium. The morphology of the films was investigated by optical and field emission scanning electron microscopy (FESEM). Fourier transform infrared (FTIR) analysis was performed in a Jasco FTIR FT/IR-615 spectrometer equipped with an ATR mode in the wave number range from 400 to $4000 \mathrm{~cm}^{-1}$. The spectra were deconvoluted by firstly smoothing the signal with a polynomial function with a 15-point Savitski-Golay smoothing function, subtracting a linear baseline, and applying a Gaussian deconvoluting curve by Origin 9 software. X-ray diffraction (XRD) was performed using a Bruker D8 Advance diffractometer with a radiation source of CuK $\alpha$

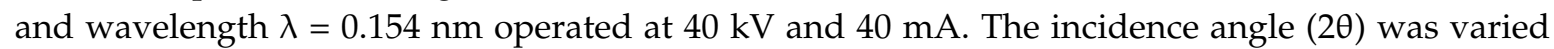
between $2^{\circ}$ and $60^{\circ}$ and the scan rate was $0.02^{\circ} / \mathrm{s}$. The tensile properties of films were measured using a universal tensile testing machine (Lloyd Instr. LR30K) with a $50 \mathrm{~N}$ static load cell. Three specimens of each sample were cut into strips (30 mm $\times 12 \mathrm{~mm} \times 0.08 \mathrm{~mm}$ ). The gauge length was $20 \mathrm{~mm}$, and the extension rate was set at $2 \mathrm{~mm} / \mathrm{min}$.

The effect of different types of coatings on bananas' freshness was evaluated by monitoring the colour change through time-lapse photography. The water permeability was determined after soaking a sponge in water and subsequently dip-coating the sponge in RS and RS/yeast solutions. The variation of the weight was monitored at different hours with a standard laboratory balance (Mettler Toledo AB135-S/FACT). The weight variation was calculated as an average of three measurements for each coating. The respiration rate of bananas was evaluated by monitoring the $\mathrm{CO}_{2}$ production. In brief, bananas were placed in a sealed FTIR chamber and the production of $\mathrm{CO}_{2}$ was monitored by measuring the evolution of the $\mathrm{CO}_{2}$ absorption peak over a period of 7 days (see Supplementary Material Figure S1). This measurement takes into account the initial background performed in air to remove the initial contribution of the carbon dioxide moisture of the air.

For the adopted transfer print process to realize the bilayer system, regenerated silk was transferred to a Parafilm film (Parafilm $\mathrm{M}^{\circledR}$, Bemis Company Inc., Neenah, WI, USA) through a direct transfer process, which consists of placing RS and RS/yeast free standing films on the receiving Parafilm substrate while applying with a hot press a pressure of $2 \mathrm{kPa}$ at $60^{\circ} \mathrm{C}$ for $15 \mathrm{~min}$; the composite material separates spontaneously from the press plates as it cools. The obtained bilayer systems were heated at $60{ }^{\circ} \mathrm{C}$ and cooled to room temperature (i.e., $\Delta \mathrm{T} \approx 40{ }^{\circ} \mathrm{C}$ ), and atomic force microscopy (AFM) was carried out to measure the wrinkle morphology using a Nanosurf easyScan DFM system in tapping mode with Gwyddion 2.51 free software for image processing.

\section{Results and Discussion}

The production method adopted for the realization of thin films with the aid of living microorganisms is schematically reported in Figure 1a. The yeast fermentation was implemented into a $\mathrm{CaCl}_{2}$-formic acid dissolution system, which can be used to produce large films (Figure $1 \mathrm{~b}$ ) with a nano-fibrillar structure (Figure 1c).

Changes in the structure of the films deposited after the fermentation-assisted silk dissolution were detected by FTIR and XRD. The $\beta$-sheet (crystalline) content was determined by the deconvolution of the amide I region (1580-1720 $\mathrm{cm}^{-1}$ ) and estimating the ratio between the peak area in the wavenumber region of $1622 \sim 1637 \mathrm{~cm}^{-1}$, which is the main absorbance region of $\beta$-sheet crystal in amide I [21], and the whole area of the amide I region comprising the peaks of the structural components, including turns (T) and random coils (R). The deconvolution of the amide I band provides an estimation of the $\beta$-sheet structure in the RS and RS/yeast of $37 \%$ and $44 \%$, respectively (Figure $1 \mathrm{~d}$,e). 
The XRD data in Figure 1f show that the RS/yeast film is characterized by diffraction peaks at $2 \Theta$ values of $20.4^{\circ}$ and $25.4^{\circ}$, corresponding to a silk I structure [22,23]. The RS film also showed silk I and silk II crystal structures, having diffraction peaks at $20.4^{\circ}$ and $29.0^{\circ}$. Compared with RS/yeast, the silk I peak at $25.0^{\circ}$ disappeared, indicating more silk II formation.

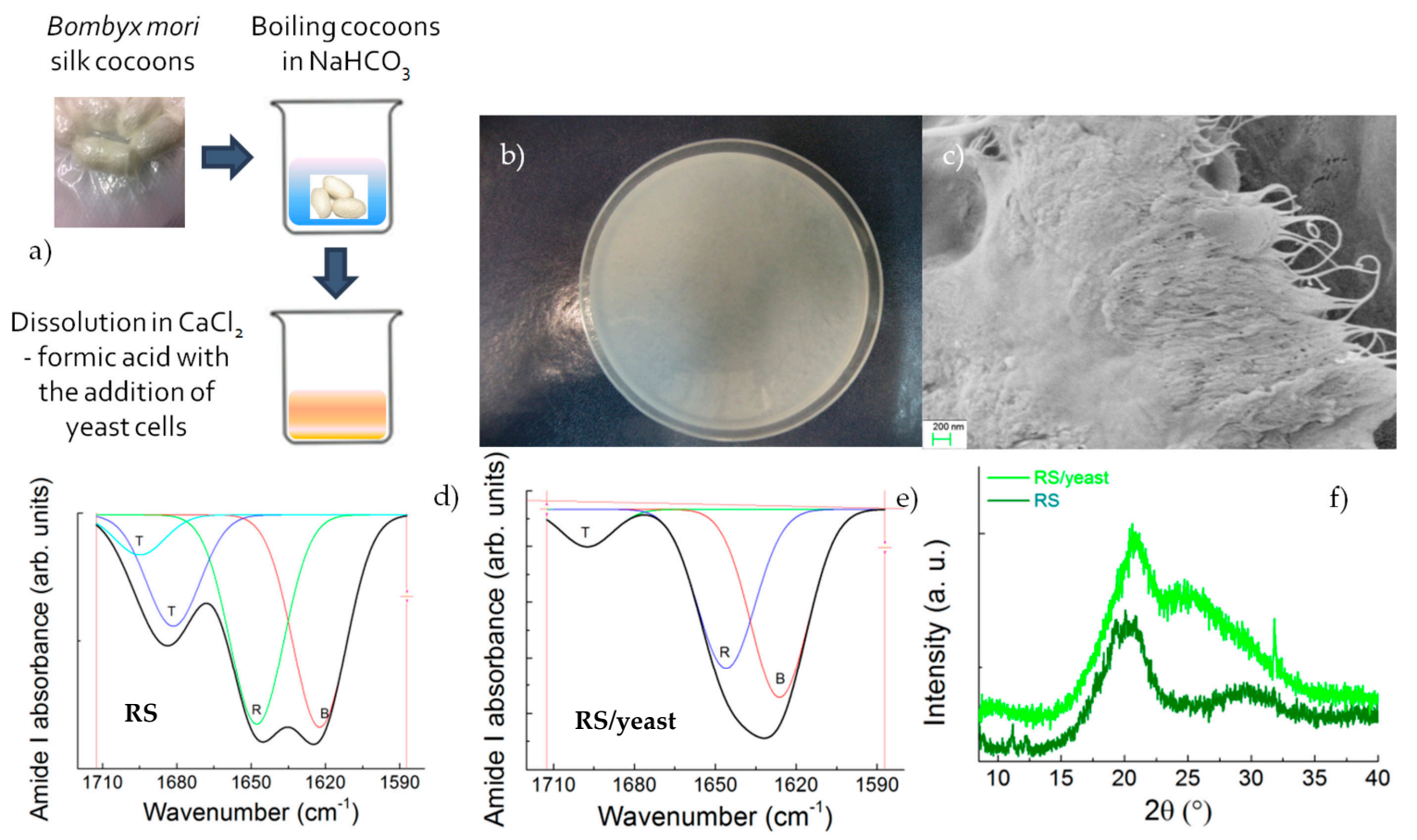

Figure 1. (a) Scheme of silk fibroin production using regenerated silk (RS); (b) Visual appearance of the RS/yeast film and (c) FESEM image of silk nanofibrils; (d,e) FTIR spectra of regenerated silk and RS/yeast films, respectively. The coloured lines represent the components of the amide I band and are indicated as $\beta$-sheets (B), random coils (R), and turns (T); (f) XRD results of regenerated silk and RS/yeast films.

The cell division of yeast occurs by budding in which a daughter cell is initiated from the mother cell followed by nuclear division and finally cell separation. The yeast cell growth reported in Figure 2 shows three main phases: a lag phase where the individual cells are activated in preparation for division; an exponential phase once the cell starts actively metabolizing shortly after the cells divide; and finally a stationary phase when the metabolism slows and the cells stop rapid cell division [24]. The factors that cause cells to enter the stationary phase are related to change in the environment typically caused by high cell density. The data reported in Figure 2a state the stability of the yeast cells to proliferate also with the presence of formic acid in the nutrient broth. The effects of RS addition during the growth curve are demonstrated in Figure 2a by measuring the OD during the cell growth. The OD curve of the yeast cells is substantially altered by the RS addition, with the effect on the lag time and final cell yield being particularly pronounced: RS/yeast cells have a lag phase of $\sim 2-3 \mathrm{~h}$, after which they proliferate rapidly; in comparison, the neat yeast cells show an increased lag phase of $\sim 10 \mathrm{~h}$. The morphology of the stationary phase for the RS/yeast system observed by means of FESEM and optical microscopy (Figure $2 b, c$ ) indicates the cell proliferation for such culture. 

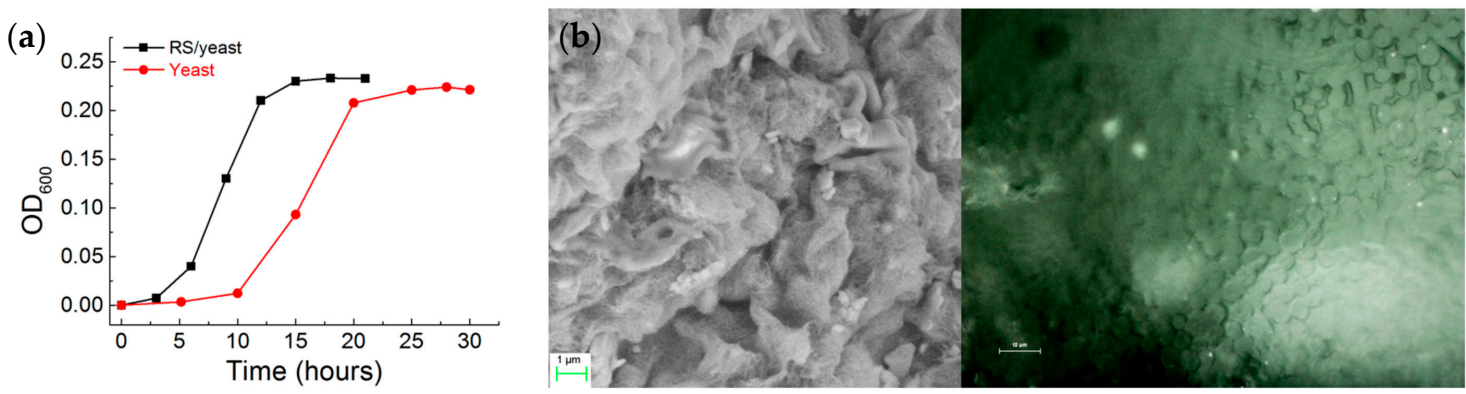

Figure 2. (a) Optical density (OD) measured at a 600-nm wavelength during growth of neat Saccharomyces cerevisiae and Saccharomyces cerevisiae in RS with sucrose until the stationary phase was reached; (b) Appearance under FESEM and optical microscope of the RS/yeast cell growth during the stationary phase.

In order to demonstrate the potential application of such a living coating in consumer-exposed food, the mechanical robustness of the films is required to withstand, for example, handling procedures.

Figure 3a represents typical stress/strain curves obtained from testing of yeast, RS, and RS/yeast samples. The maximum average toughness (i.e., the area underlying the stress/strain curves) obtained from the RS/yeast sample was $0.14 \mathrm{MPa}$ (Figure 3b), the highest average strength (i.e., the stress at the ultimate strain) obtained was $1.26 \mathrm{MPa}$, and the maximum elastic modulus recorded was 37.2 MPa. The improved mechanical properties with the fermentation-based dissolution of silkworm silk fibers agree with our previous studies reported for the fermentation-assisted synthesis of bionic composites $[19,25]$. In these studies, addition of carbon nanotubes (CNTs) and/or graphene in the fermentation broth resulted in composites with a higher toughness value. In our studies, tensile tests on dried composite films were rationalized in terms of a CNT cell-bridging mechanism where the strongly enhanced strength of the composite is governed by the adhesion energy between the bridging CNTs and the matrix. The presence of glucose can plasticize regenerated silks and increase the ultimate strain leading to toughness values (see Table 1 ) that are comparable to those measured for traditional biopolymers used for food packaging $[26,27]$ being in our case as added value the edibility of the coating.
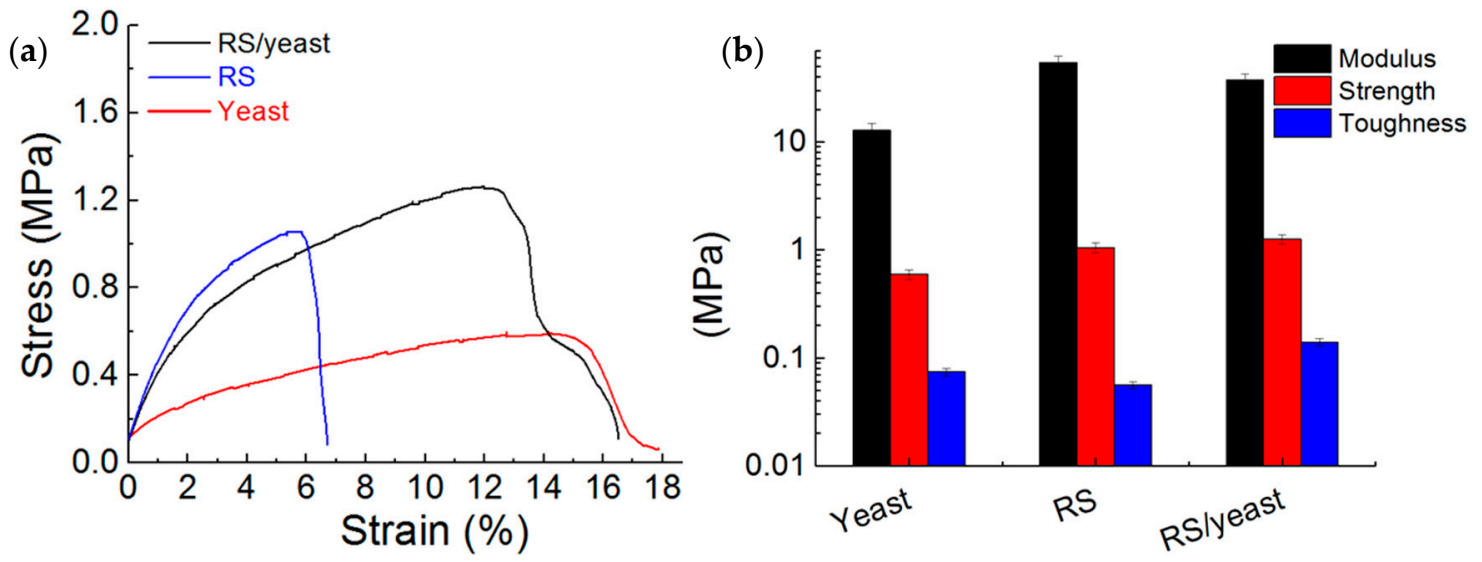

Figure 3. (a) Stress/strain curves from testing of yeast, RS, and RS/yeast samples. The curves represent an analysis performed on three different samples; (b) Effect of yeast fermentation on modulus, strength, and toughness of RS film. The modulus, strength, and toughness of neat yeast film have been reported for comparative purposes. 
Table 1. Mechanical properties of various biopolymers for food packaging [27]. $\sigma^{*}$, specific tensile strength; $E^{*}$, specific tensile modulus; $\varepsilon$, ultimate strain.

\begin{tabular}{ccccc}
\hline Type of Biopolymer & Toughness $\mathbf{( M P a )}$ & $\left.\boldsymbol{\sigma}^{*} \mathbf{( N m} / \mathbf{g}\right)$ & $\mathbf{E}^{*} \mathbf{( k N m / g )}$ & $\mathbf{E}(\mathbf{\%})$ \\
\hline RS/yeast (this work) & 0.14 & 1.1 & 0.032 & 15.4 \\
PLA & 0.26 & 16.8 & 0.3 & 2.5 \\
PLLA & 0.23 & 40.0 & 2.2 & 3.0 \\
PDLLA & 0.28 & 22.1 & 0.8 & 2.0 \\
PDLLA/PGA50/50 & 0.41 & 30.9 & 0.8 & 2.0 \\
\hline
\end{tabular}

In general, coatings for food packaging beyond the mechanical robustness should exert low permeability to water vapors; fruit dehydration is, in general, an indicator of the breakdown of the protective skin, which results in loss of turgor and water evaporation. We observe that the increase in beta-sheet content yields a lower water permeability through the RS/yeast membrane as indicated by the lower variation in the initial weight of soaked sponges coated with different types of coatings as reported in Figure 4a (see Supplementary Material Figure S2). These results are in agreement with those obtained by Omenetto et al. [10], who showed that when the silk fibroin beta-sheet content is in the range of $36-58 \%$, the water vapour permeability is 5 times smaller than that measured for the film with a lower beta-sheet content.

Many fresh fruits have high metabolic activity, and due to microbial attack it results in a short conservation time, colour change (Figure $4 b$ ), and off-flavour. The change in colour of fresh fruit, in particular, is associated with ethylene production and cell respiration. To evaluate the exploitation of RS/yeast film as a barrier coating, the change in color of coated and non-coated fresh bananas was evaluated (Figure $4 \mathrm{~b}$ ). Time-lapse photography shows that an RS/yeast coating decreases the fruit degradation when compared to uncoated or RS-coated fruit at day 7. During the continuing metabolism of the fresh fruit, oxygen is transformed into carbon dioxide; thus, gas permeation through a coating film plays a crucial role in fruit storage. To prevent the spoilage of fresh fruits, it is necessary to reduce the breathing process. In our case, the higher beta-sheet content of the RS/yeast film decreases the production of $\mathrm{CO}_{2}$, which indicated a decrease in the respiration rate of the fruits (Figure 4c).

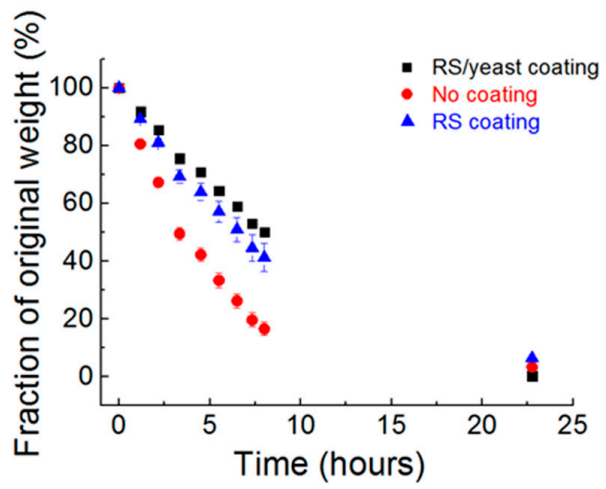

(a)

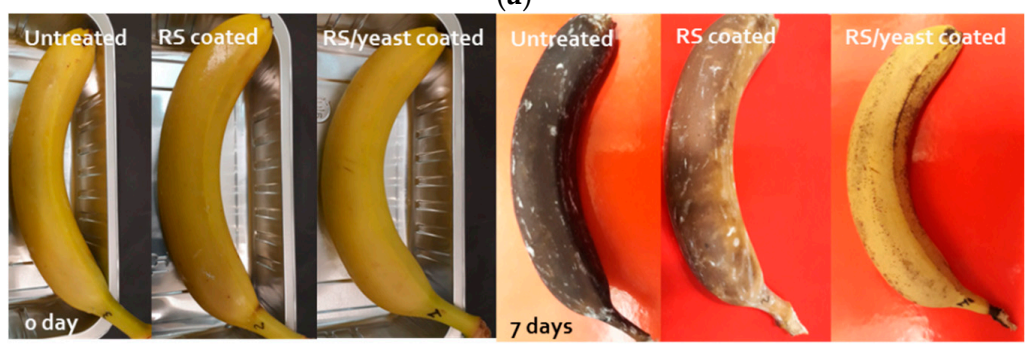

(b)

Figure 4. Cont. 


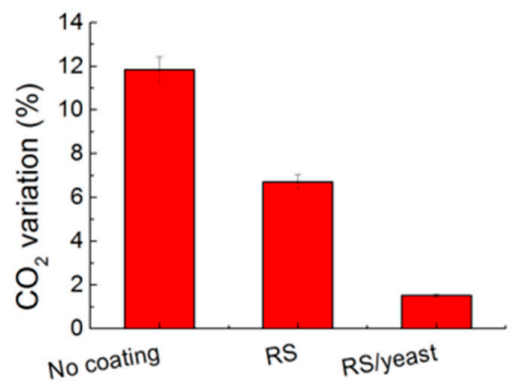

(c)

Figure 4. (a) Weight loss of sponges soaked in water and stored for up to $25 \mathrm{~h}$ at $23{ }^{\circ} \mathrm{C}$ and $32 \%$ relative humidity (RH). Sponges were stored without coating or after dip coating with RS and RS/yeast suspensions, respectively; (b) Evaluation of bananas' degradation. Fruits were stored at $23{ }^{\circ} \mathrm{C}$ and $32 \%$ $\mathrm{RH}$ as received and after coating with a silk/yeast film. Time lapse photography of banana degradation, indicating that the silk/yeast coating reduces the degradation rate; (c) $\mathrm{CO}_{2}$ variation of uncoated, RS-coated, and RS/yeast-coated bananas, respectively.

Another very interesting property of such silk nanofibrils relies on their ability to self-assemble, giving rise to a sol-gel transition with rapid gelation time induced by the presence of salts [28,29]. Pregelation occurs when a fresh solution has a $\beta$-sheet content of about $20 \%$ with negligible intermolecular bindings; gelation is then induced by interchain interactions that become irreversible with the formation of the $\beta$-sheet intermolecular structures of the gel phase [29]. In our case, the gelation was observed when $\mathrm{KNO}_{3}$ salt was added to a silk nanofibrils/yeast/formic acid solution (Figure 5). Without salt, the RS/yeast retains with time a sol characteristic (Figure 5a). In comparison to the sol RS/yeast solution, the RS/yeast with salt solution transforms into a semi-solid gel within several hours together with the appearance of a strong infrared absorption peak at $1626 \mathrm{~cm}^{-1}$ due to the formation of strong $\beta$-sheet structures (Figure $5 b$ ).

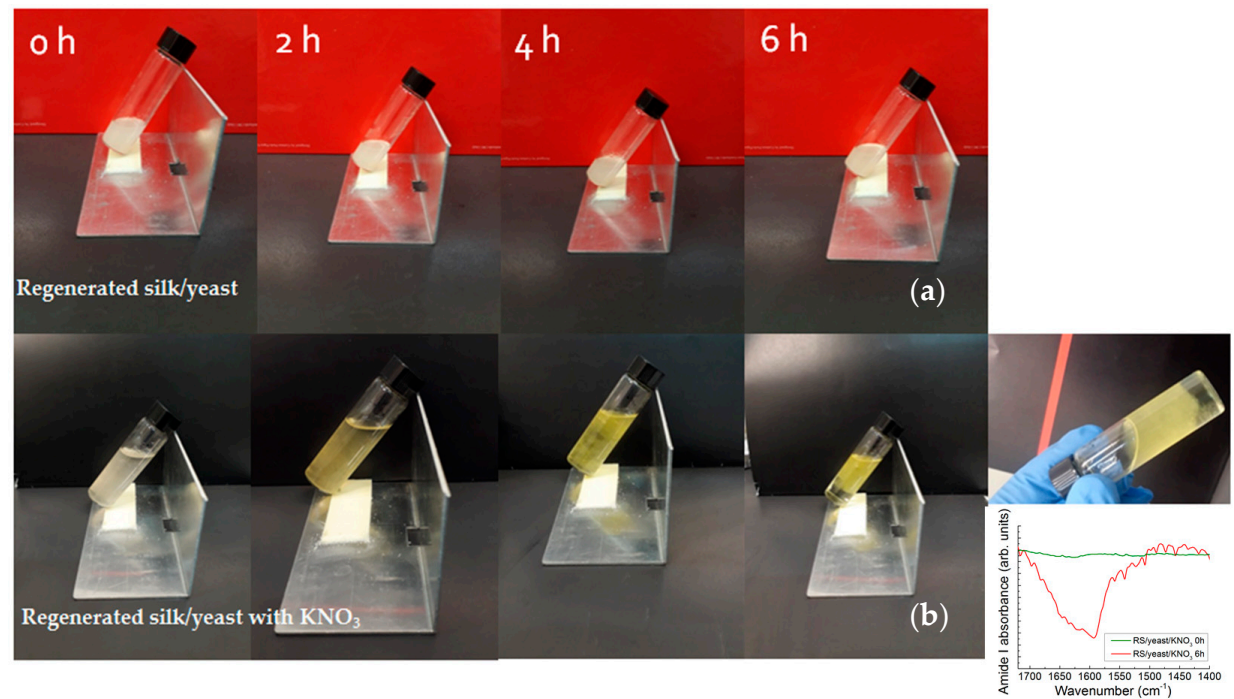

Figure 5. Dynamic optical morphology of (a) RS/yeast and (b) RS/yeast/ $\mathrm{KNO}_{3}$ solutions resulting at different times (temperature $37^{\circ} \mathrm{C}$ ). The inset of panel $(\mathbf{b})$ shows the evolution of the amide I FTIR band of the RS/yeast/ $\mathrm{KNO}_{3}$ solution with time and gelation of the RS/yeast/ $\mathrm{KNO}_{3}$ solution.

Considering the application of controlling the food cold chain, it is essential to design a bilayer packaging system where the mechanical properties of the top skin layer when laminated onto a soft substrate will be beneficial for the creation of temperature-driven surface patterning. Figure 6a shows the RS and RS/yeast films laminated onto a paraffin wax substrate. Wrinkle formation is typically 
connected to the high thermal expansion coefficient of the substrate used for the transfer. Parafilm is used worldwide in research laboratories as a self-adhesive and sealant plastic foil. It is soft (tensile strength $\approx 2.0 \mathrm{MPa}$ ) with a high thermal expansion coefficient (i.e., $0.89 \times 10^{-3} \mathrm{~K}^{-1}$ ) and due to its low melting point $\left(\approx 60^{\circ} \mathrm{C}\right)$, it becomes adhesive when applying heat during lamination and sticks strongly to the receiving material. The formation of wrinkles occurs to minimize the total potential energy of the skin layer and the substrate induced by thermal expansion. The strategy for the realization of heat-driven wrinkle patterns is illustrated in Figure 6b; once heated, the paraffin wax upon cooling to room temperature generates a compressive stress at the interface of the bilayer sample owing to the considerable mismatch between the modulus and thermal expansion ratio of the substrate and the stiff top layer made of RS or RS/yeast [30]. The wrinkling formation and height analysis of wrinkles can be determined with the use of the AFM. The AFM images reported in Figure $6 \mathrm{c}$ show that the crumpled surface appears unfolded and smoothed once heated. Height histograms spanning a few wrinkles of the RS and RS/yeast cooled samples are given in Figure $6 \mathrm{~d}$ and indicate that the step heights are $\approx 1 \mu \mathrm{m}$ high. The highest peak distributions indicate the periodicity in the surface morphology. Furthermore, it can be easily noticed that film layers form long line-shaped wrinkles (length in the order of $2 \mu \mathrm{m}$ ). Moreover, it is clearly evidenced by AFM height histograms that the film layer between two successive wrinkles remains at the same height level, suggesting that the film is now lying upon its substrate (Figure 6d).

Further analysis of the AFM images reveals that the size of the peak (wrinkles' wavelength) distribution decreased in the RS/yeast sample, indicating that, among the samples studied, the stiffer film layer produced the smallest periods and amplitudes. The periods of the wrinkle structures were measured by using Gwyddion 2.51 free software, and the amplitude (A) and wavelength $(\lambda)$ of the wrinkled structures are reported in Table 2.

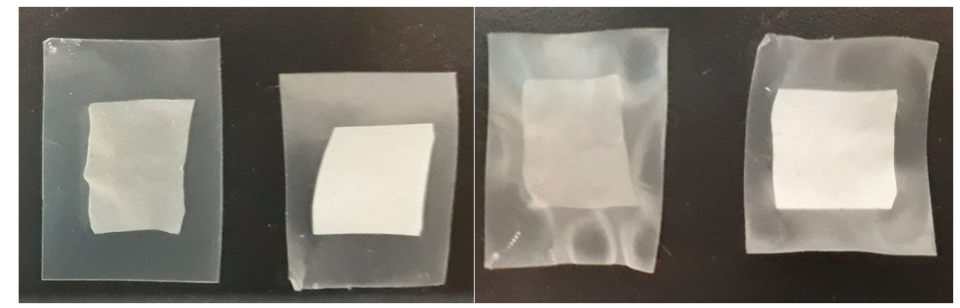

(a)

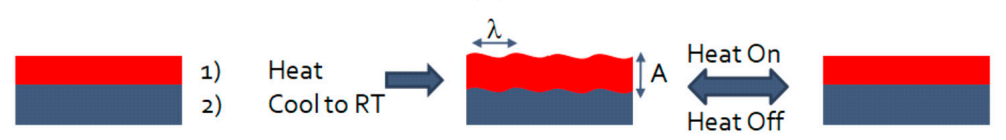

(b)

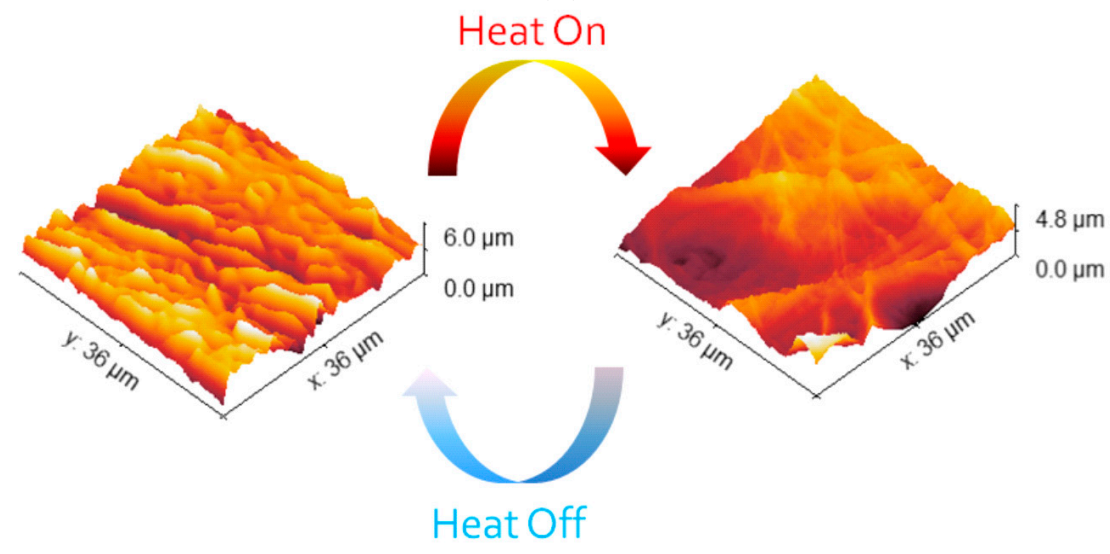

(c)

Figure 6. Cont. 

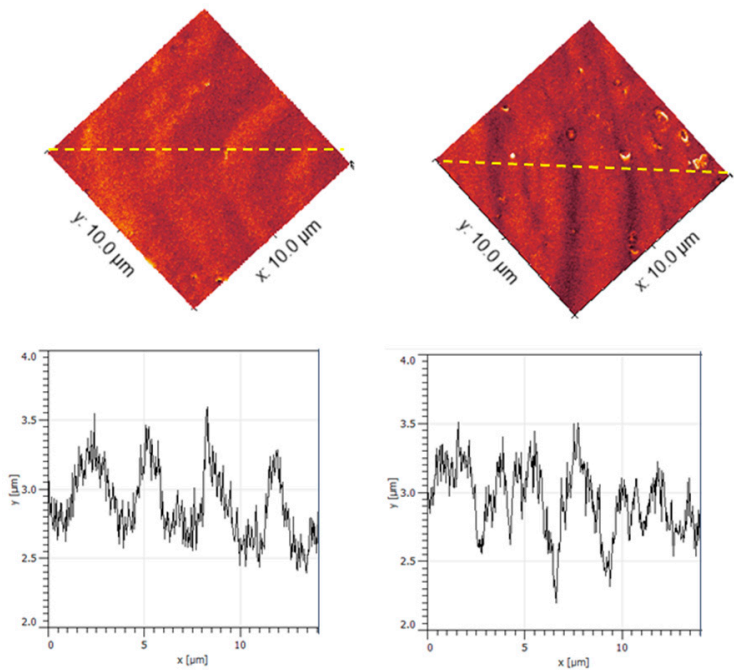

(d)

Figure 6. (a) Photographs of RS/yeast/paraffin and RS/paraffin bilayer systems before (left) and after (right) the wrinkle activation; (b) Schematic illustration of temperature-driven wrinkling. The bilayer system is flat at room temperature and the heat induces the temperature to increase; thus, the thermal expansion of the paraffin substrate results in an increase in the compressive strain of the bilayer systems once they have cooled down to room temperature with the appearance of the wrinkles. Once a wrinkled state is activated, the heat/temperature can again induce thermal expansion of the paraffin substrate, resulting in the reversibility of the temperature-driven wrinkles; (c) three-dimensional (3D) AFM images showing the reversibility of the temperature-driven wrinkles; (d) AFM images and the related profile of the yellow lines passing through the RS (left) and RS/yeast (right) film layers.

Table 2. Theoretical and experimental (estimated by AFM images and related profiles reported in Figure $6 \mathrm{~d}$ ) amplitude and wavelength of the different skin layers with $\mathrm{a}=0.4$.

\begin{tabular}{ccccc}
\hline Sample & $\mathbf{A}_{\text {Theor. }}(\mu \mathrm{m})$ & $\boldsymbol{\lambda}_{\text {Theor. }}(\mu \mathrm{m})$ & $\mathbf{A}_{\text {Exp. }}(\mu \mathrm{m})$ & $\boldsymbol{\lambda}_{\text {Exp. }}(\mu \mathrm{m})$ \\
\hline RS/paraffin & 2.72 & 1.83 & 1.23 & 2.93 \\
RS/yeast/paraffin & 2.20 & 2.21 & 1.04 & 2.14 \\
\hline
\end{tabular}

The amplitude and the wavelength of the wrinkles depend on the thickness and mechanical properties of the skin layer and the substrate according to linear bucking theory [31-35], which can be expressed as:

$$
\mathrm{A}=\mathrm{h}_{\mathrm{f}}\left(\left(\sigma_{0}-\sigma_{\mathrm{c}}\right) / \sigma_{\mathrm{c}}\right)^{1 / 2} / \mathrm{a}
$$

and

$$
\lambda=4.36 \mathrm{~h}_{\mathrm{f}}\left(\mathrm{E}_{\mathrm{f}}\left(1-v_{\mathrm{s}}^{2}\right) /\left(\mathrm{E}_{\mathrm{s}}\left(1-v_{\mathrm{f}}^{2}\right)\right)^{1 / 3}-2 \mathrm{~A}(1-\mathrm{a}) / \mathrm{a}\right.
$$

where $\sigma_{\mathrm{C}}$ refers to the critical stress to wrinkle formation and is given as $^{33}$

$$
\sigma_{\mathrm{C}}=(1 / 4)\left(\mathrm{E}_{\mathrm{f}}{ }^{\prime}\right)^{1 / 3}\left(\mathrm{E}_{\mathrm{s}}^{\prime}\right)^{2 / 3}
$$

and $\sigma_{0}$ is the compressive stress of the film layer at a temperature below the heating temperature, which is given by the equation [36]:

$$
\sigma_{0}=\left(E_{\mathrm{f}}\left(\alpha_{\mathrm{s}}-\alpha_{\mathrm{f}}\right) \Delta \mathrm{T}\right) /\left(1-v_{\mathrm{f}}\right)
$$

where $E^{\prime}=E /\left(1-v^{2}\right)$ and the subscripts $f$ and $s$ refer to the film layer and the substrate of the bilayer system, respectively, and E', E, and $v$ are the plane modulus, Young's modulus, and Poisson's ratio, 
respectively. $h_{\mathrm{f}}$ is the film thickness and $0 \leq \mathrm{a} \leq 1$ is an adhesion parameter that we have introduced (ideally $\mathrm{a}=1$ ) for accounting for the non-ideal bonding between film and substrate (imposing the film's inextensibility and simply assuming squared-shape wrinkles, i.e., $2 \mathrm{~A}+\lambda$ cost). The Young's modulus for RS, RS/yeast, and paraffin are $54 \mathrm{MPa}, 37 \mathrm{MPa}$, and $1.4 \mathrm{MPa}$ [18], respectively, and $v_{\mathrm{f}}=0.5$. The applied strain $\varepsilon$ when the bilayer system is heated is calculated as $\varepsilon=\left(\alpha_{s}-\alpha_{\mathrm{f}}\right) \mathrm{x} \Delta \mathrm{T}$, where $\alpha_{\mathrm{s}}$ and $\alpha_{\mathrm{f}}$ are the thermal expansion coefficients with $\alpha_{\mathrm{s}}>\alpha_{\mathrm{f}}$. Finally, the theoretical wavelength and amplitude values obtained from Equations (1) and (2) are reported in Table 2 and compared with the experimental findings by fitting the single parameter $a$.

\section{Conclusions}

Here, we described how the activation of the metabolic activity of microorganisms with regenerated silk increases the crystalline content of RS fibroin, reducing the water permeability by $\approx 30 \%$ and increasing the shelf-life of perishable food over a period of 7 days. Then, we reported a method which consists of transfer printing the prepared freestanding RS and RS/yeast layer films onto a self-adherent Parafilm substrate. By increasing the applied strain $(\varepsilon)$ via thermal heating of the high thermal expansion paraffin-based substrate, we observed an increase of the wrinkles' wavenumbers in the RS/yeast skin layer due to a high mechanical mismatch between the film layer and the paraffin substrate. This approach can be used in the real design of smart coatings by controlling the mechanical properties as the designing parameter for tuning the wrinkle morphologies. Moreover, the proposed method for coupling two different systems could be considered as a valid alternative for laminating two or more flexible layers without a bonding agent. Such solventless laminates could be much more environmentally friendly and result in a low-cost product for high-speed production lines.

Supplementary Materials: The following are available online at http:/ /www.mdpi.com/2079-4991/8/7/518/s1, Figure S1: Evolution of the $\mathrm{CO}_{2}$ absorption peak over period of 7 days for (left) RS/yeast and (right) RS coatings, respectively; Figure S2: Water-soaked sponges with different types of coatings.

Author Contributions: Conceptualization, L.V. and N.M.P.; Methodology, L.V. and N.M.P.; Investigation, S.B.B.; Data Curation, S.B.B.; Writing (Original Draft Preparation), L.V. and N.M.P.; Writing (Review and Editing), L.V. and N.M.P.

Funding: N.M.P. is supported by the European Commission under the Graphene Flagship Core 2 grant No. 785219 (WP14 "Polymer Composites") and FET Proactive "Neurofibres" grant No. 732344 as well as by the Italian Ministry of Education, University and Research (MIUR) under the "Departments of Excellence" grant L.232/2016. L.V. is supported by the Italian Ministry of Education, University and Research (MIUR) under the "Departments of Excellence" grant L.232/2016.

Acknowledgments: Miguel-Angle Lopez-Manchado (Instituto de Ciencia y Tecnología de Polímeros, ICTP-CSIC, Madrid) is kindly acknowledged for the XRD analysis.

Conflicts of Interest: The authors declare no conflict of interest.

\section{References}

1. Cleveland, J.; Montville, T.J.; Nes, I.F.; Chikindas, M.L. Bacteriocins: Safe, natural antimicrobials for food preservation. Int. J. Food Microbiol. 2001, 71, 1-20. [CrossRef]

2. Paul Ross, R.; Morgan, S.; Hill, C. Preservation and fermentation: Past, present and future. Int. J. Food Microbiol. 2002, 79, 3-16. [CrossRef]

3. Synowiecki, J.; Al-Khateeb, N.A. Production, properties, and some new applications of chitin and its derivatives. Crit. Rev. Food Sci. Nutr. 2003, 43, 145-171. [CrossRef] [PubMed]

4. Siracusa, V.; Rocculi, P.; Romani, S.; Dalla Rosa, M. Biodegradable polymers for food packaging: A review. Trends Food Sci. Technol. 2008, 19, 634-643. [CrossRef]

5. Kim, P.; Hu, Y.; Alvarenga, J.; Kolle, M.; Suo, Z.; Aizenberg, J. Rational Design of Mechano-Responsive Optical Materials by Fine Tuning the Evolution of Strain-Dependent Wrinkling Patterns. Adv. Opt. Mater. 2013, 1, 381-388. [CrossRef]

6. Bowden, N.; Huck, W.T.S.; Paul, K.E.; Whitesides, G.M. The controlled formation of ordered, sinusoidal structures by plasma oxidation of an elastomeric polymer. Appl. Phys. Lett. 1999, 75, 2557-2559. [CrossRef] 
7. Ohzono, T.; Suzuki, K.; Yamaguchi, T.; Fukuda, N. Tunable optical diffuser based on deformable wrinkles. Adv. Opt. Mater. 2013, 1, 374-380. [CrossRef]

8. Kim, D.H.; Viventi, J.; Amsden, J.J.; Xiao, J.; Vigeland, L.; Kim, Y.S.; Blanco, J.A.; Panilaitis, B.; Frechette, E.S.; Contreras, D.; et al. Dissolvable films of silk fibroin for ultrathin conformal bio-integrated electronics. Nat. Mater. 2010, 9, 511-517. [CrossRef] [PubMed]

9. Tao, H.; Brenckle, M.A.; Yang, M.; Zhang, J.; Liu, M.; Siebert, S.M.; Averitt, R.D.; Mannoor, M.S.; McAlpine, M.C.; Rogers, J.A.; et al. Silk-based conformal, adhesive, edible food sensors. Adv. Mater. 2012, 24, 1067-1072. [CrossRef] [PubMed]

10. Marelli, B.; Brenckle, M.A.; Kaplan, D.L.; Omenetto, F.G. Silk fibroin as edible coating for perishable food preservation. Sci. Rep. 2016, 6, 25263. [CrossRef] [PubMed]

11. Lawrence, B.D.; Pan, Z.; Liu, A.; Kaplan, D.L.; Rosenblatt, M.I. Human corneal limbal epithelial cell response to varying silk film geometric topography in vitro. Acta Biomater. 2012, 8, 3732-3743. [CrossRef] [PubMed]

12. Lawrence, B.D.; Marchant, J.K.; Pindrus, M.A.; Omenetto, F.G.; Kaplan, D.L. Silk film biomaterials for cornea tissue engineering. Biomaterials 2009, 30, 1299-1308. [CrossRef] [PubMed]

13. Lawrence, B.D.; Wharram, S.; Kluge, J.A.; Leisk, G.G.; Omenetto, F.G.; Rosenblatt, M.L.; Kaplan, D.L. Effect of hydration on silk film material properties. Macromol. Biosci. 2010, 10, 393-403. [CrossRef] [PubMed]

14. Brenckle, A.M.; Kaplan, D.L.; Omenetto, F.G. Direct Transfer Printing of Water Hydrolyzable Metals onto Silk Fibroin Substrates through Thermal-Reflow-Based Adhesion. Adv. Mater. Interfaces 2016, 3, 1600094. [CrossRef]

15. Jay, S.C. The cocoon of the honey bee, Apis mellifera. Can. Entomol. 1964, 96, 784-792. [CrossRef]

16. Hepburn, H.R.; Kurstjens, S.P. The combs of honeybees as composite materials. Apidologie 1988, 19, 25-36. [CrossRef]

17. Dorset, D.L. The crystal structure of waxes. Acta Crystallogr. B 1995, 51, 1021-1028. [CrossRef] [PubMed]

18. Valentini, L.; Bittolo Bon, S.; Lopez-Manchado, M.-A.; Mussolin, L.; Pugno, N. Development of conductive paraffin/graphene films laminated on fluoroelastomers with high strain recovery and anti-corrosive properties. Compos. Sci. Technol. 2017, 149, 254-261. [CrossRef]

19. Valentini, L.; Bittolo Bon, S.; Signetti, S.; Tripathi, M.; Iacob, E.; Pugno, N.M. Fermentation based carbon nanotube multifunctional bionic composites. Sci. Rep. 2016, 6, 27031. [CrossRef] [PubMed]

20. Ling, S.; Zhang, Q.; Kaplan, D.L.; Omenetto, F.; Buehler, M.J.; Qin, Z. Printing of stretchable silk membranes for strain measurements. Lab Chip 2016, 16, 2459-2466. [CrossRef] [PubMed]

21. Hu, X.; Kaplan, D.; Cebe, P. Determining Beta-Sheet Crystallinity in Fibrous Proteins by Thermal Analysis and Infrared Spectroscopy. Macromolecules 2006, 39, 6161-6170. [CrossRef]

22. Lu, Q.; Hu, X.; Wang, X.; Kluge, J.A.; Lu, S.; Cebe, P.; Kaplan, D.L. Water-insoluble silk films with silk I structure. Acta Biomater. 2010, 6, 1380-1387. [CrossRef] [PubMed]

23. Anderson, J.P. Morphology and crystal structure of a recombinant silk-like molecule, SLP4. Biopolymers 1998, 45, 307-321. [CrossRef]

24. Warringer, J.; Ericson, E.; Fernandez, L.; Nerman, O.; Blomberg, A. High-resolution yeast phenomics resolves different physiological features in the saline response. Proc. Natl. Acad. Sci. USA 2003, 100, 15724-15729. [CrossRef] [PubMed]

25. Valentini, L.; Bon, S.B.; Signetti, S.; Pugno, N.M. Graphene-Based Bionic Composites with Multifunctional and Repairing Properties. ACS Appl. Mater. Interfaces 2016, 8, 7607-7612. [CrossRef] [PubMed]

26. Seidel, A.; Liivak, O.; Calve, S.; Adaska, J.; Ji, G.; Yang, Z.; Grubb, D.; Zax, D.B.; Jelinski, L.W. Regenerated Spider Silk: Processing, Properties, and Structure. Macromolecules 2000, 33, 775-780. [CrossRef]

27. Van de Velde, K.; Kiekens, P. Biopolymers: Overview of several properties and consequences on their applications. Polym. Test. 2002, 21, 433-442. [CrossRef]

28. Im, D.S.; Kim, M.H.; Yoon, Y.I.; Park, W.H. Gelation behaviors and mechanism of silk fibroin according to the addition of nitrate salts. Int. J. Mol. Sci. 2016, 17, 1697. [CrossRef] [PubMed]

29. Matsumoto, A.; Chen, J.; Collette, A.L.; Kim, U.J.; Altman, G.H.; Cebe, P.; Kaplan, D.L. Mechanisms of silk fibroin sol-gel transitions. J. Phys. Chem. B 2006, 110, 21630-21638. [CrossRef] [PubMed]

30. Hou, H.; Yin, J.; Jiang, X. Reversible diels-alder reaction to control wrinkle patterns: From dynamic chemistry to dynamic patterns. Adv. Mater. 2016, 28, 9126-9132. [CrossRef] [PubMed]

31. Rodríguez-Hernández, J. Wrinkled interfaces: Taking advantage of surface instabilities to pattern polymer surfaces. Prog. Polym. Sci. 2015, 42, 1-41. [CrossRef] 
32. Chen, C.-M.; Yang, S. Wrinkling instability in polymer films and their applications. Polym. Int. 2012, 61, 1041-1047. [CrossRef]

33. Bowden, N.; Brittain, S.; Evans, A.G.; Hutchinson, J.W.; Whitesides, G.M. Spontaneous formation of ordered structures in thin films of metals supported on an elastomeric polymer. Nature 1998, 393, 146-149.

34. Stafford, C.M.; Harrison, C.; Beers, K.L.; Karim, A.; Amis, E.J.; VanLandingham, M.R.; Kim, H.-C.; Volksen, W.; Miller, R.D.; Simonyi, E.E. A buckling-based metrology for measuring the elastic moduli of polymeric thin films. Nat. Mater. 2004, 3, 545-550. [CrossRef] [PubMed]

35. Wang, Q.; Zhao, X. Beyond wrinkles: Multimodal surface instabilities for multifunctional patterning. MRS Bull. 2016, 41, 115-122. [CrossRef]

36. Ohring, M. The Material Science of Thin Films; Academic: San Diego, CA, USA, 1992.

(C) 2018 by the authors. Licensee MDPI, Basel, Switzerland. This article is an open access article distributed under the terms and conditions of the Creative Commons Attribution (CC BY) license (http:/ / creativecommons.org/licenses/by/4.0/). 